\title{
THE MULTIPURPOSE NEW WIND TUNNEL STU
}

\author{
Ol'ga HUBOVÁ ${ }^{1, *}$, Peter LOBOTKA ${ }^{1}$ \\ ${ }^{1}$ Slovak University of Technology, Faculty of Civil Engineering, Slovak Republic. \\ corresponding author: olga.hubova@stuba.sk.
}

\section{Abstract}

BLWT STU tunnel, which is currently in test mode, will in its two measuring sections allow to prepare measurements with laminar and turbulent wind flow. The front section will fulfill technical parameters of steady flow for testing sectional models and dynamically similar models. In the rear operating section it is necessary to reproduce correctly the roughness of the earth surface covering different terrain categories and to prepare boundary layer suitable for experimental testing. Article deals with the brief description of the preparation and testing laminar flow and boundary layer for the urban terrain, which was simulated with rough elements and barriers of different heights. The attention is focused in getting get at least 1 meter height of boundary layer, which allows to optimize scale similarity of model.
\end{abstract}

\section{Keywords:}

Experimental technic; Wind engineering;

Wind flow;

Wind load;

Wind tunnel.

\section{Introduction}

A newly built BLWT STU wind tunnel enables primarily the experimental assessment of static and dynamic effects of wind on reduced models of buildings and structures or their parts, which are positioned in the turbulent flow, simulating the natural wind in various terrain categories. Boundary wind tunnel STU in Bratislava was designed with open circuit scheme (Fig.1) with overall length $26,3 \mathrm{~m}$ and the operation sector of cross-section 2,6 $\times 1,6 \mathrm{~m}$ and length $14,6 \mathrm{~m}$ can be divided into front and rear test sections. This device in Bratislava - Trnávka is constructed as a vacuum tunnel. This means that the pressure in the out-of-operation tunnel is equal to the outside barometric pressure. During operation, the static pressure in tunnel decreases counter to the dynamic pressure.

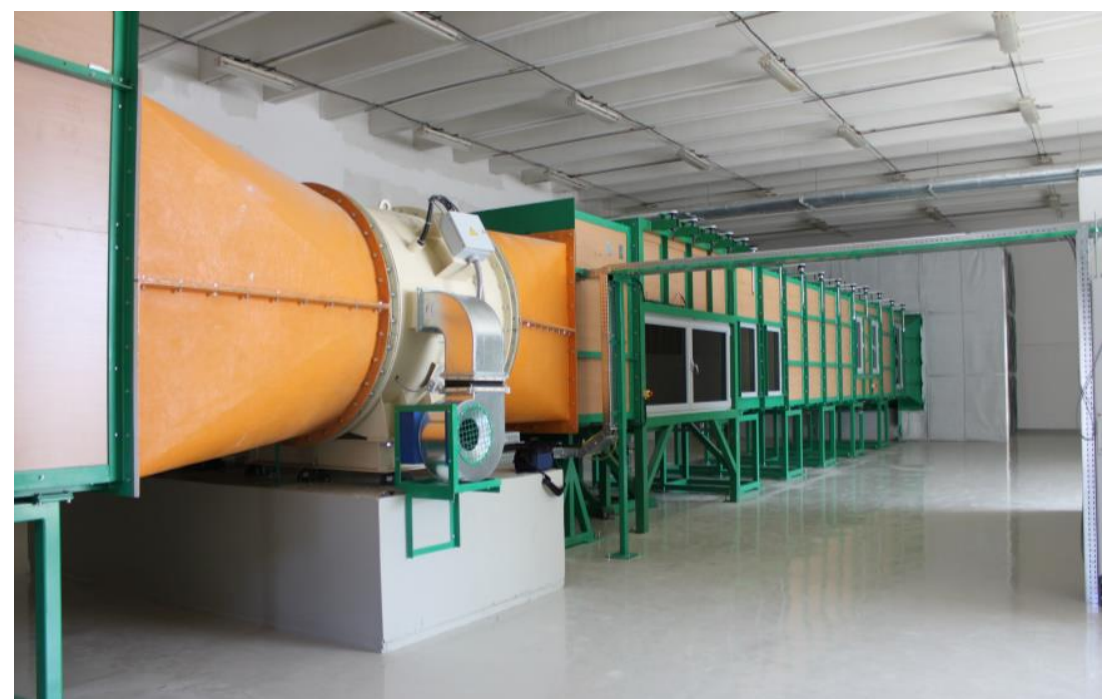

Fig. 1: General view of BLWT STU wind tunnel in Bratislava. 


\section{The front section}

Test section with laminar flow will be used for measurements of aero-elastic instabilities for the slender structures with more than fundamental mode and also for the sectional models. The range of stream velocity varies from 0,2 to $32 \mathrm{~m} / \mathrm{s}$. The front section (Fig. 2) is equipped by the reference sensor - Prandtl sensor (Pitot static tube) for assessment of dynamic air pressure and measuring the overall and static pressure.

Using digital probe ALMEMO FVAD 35 TH5K2 detailed measurements of the horizontal profiles of wind speed were made in the front section. Barometric pressure: $p_{b}=98770[\mathrm{~Pa}]$, temperature: $T=18,3-18,6\left[{ }^{\circ} \mathrm{C}\right]$, air density: $\rho=1,17548-1,1742[\mathrm{~kg} / \mathrm{m} 3]$.

Results of experimental measurements of wind flow can be seen in Table 1 and in Fig. 3, where $U$ is mean wind speed and $U_{r}$ is reference wind speed on Prandtl sensor.

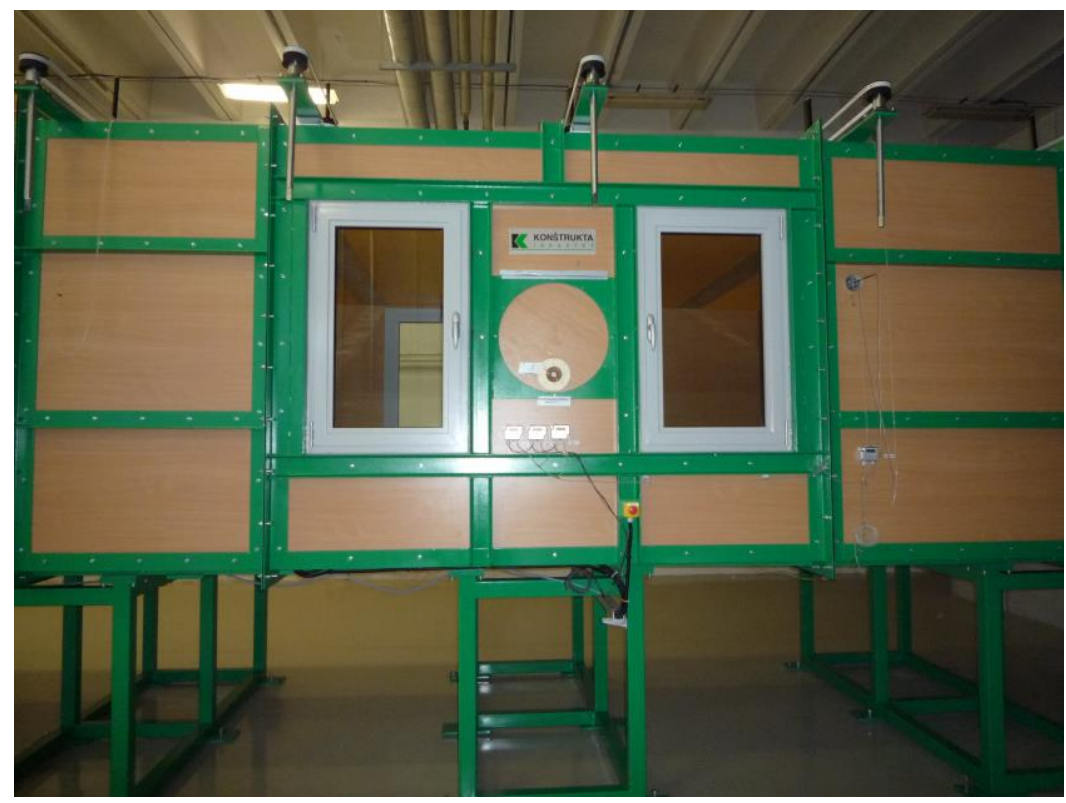

Fig. 2: The view of front wind tunnel section.

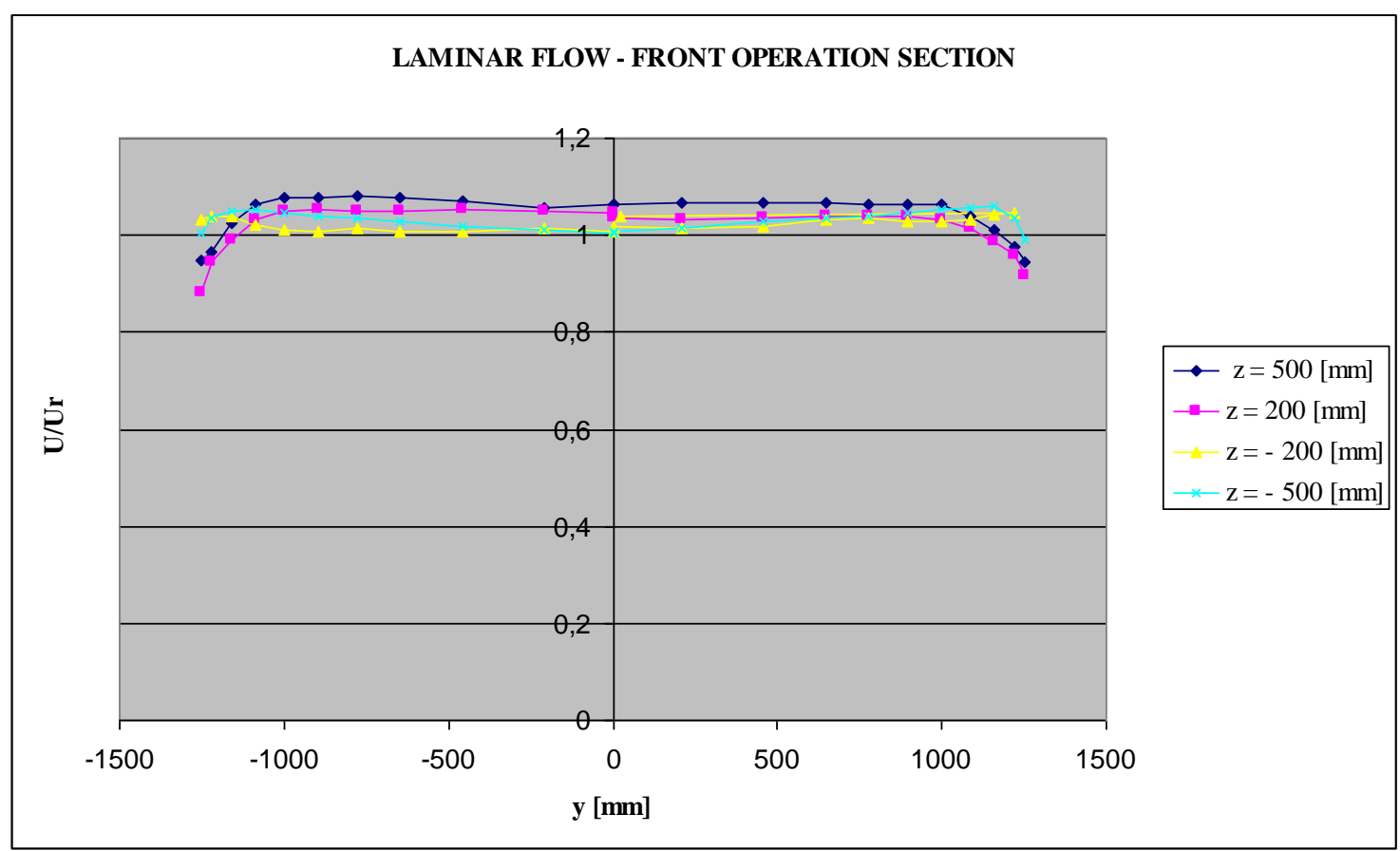

Fig. 3: Laminar flow at different heights in the cross section of front area. 
Table 1: Measuring of wind speed at basic height $800 \mathrm{~mm} \pm 200 \mathrm{~mm}$.

\begin{tabular}{|c|c|c|c|c|c|c|c|c|}
\hline & \multicolumn{4}{|c|}{$z=+200 \mathrm{~mm}$} & \multicolumn{4}{|c|}{$z=-200 \mathrm{~mm}$} \\
\hline$y \quad[\mathrm{~mm}]$ & $q[\mathrm{~Pa}]$ & $U_{r}[\mathrm{~m} / \mathrm{s}]$ & $\boldsymbol{U}[\mathrm{m} / \mathrm{s}]$ & $U / U_{r}$ & $q[\mathrm{~Pa}]$ & $U_{r}[\mathrm{~m} / \mathrm{s}]$ & $\boldsymbol{U}[\mathrm{m} / \mathrm{s}]$ & $U / U_{r}$ \\
\hline-1250 & 123 & 14,466 & 12,75 & 0,8814 & 123,2 & 14,48 & 14,96 & 1,0331 \\
\hline-1220 & 123 & 14,466 & 13,64 & 0,9429 & 123,2 & 14,48 & 15,07 & 1,0407 \\
\hline-1160 & 123 & 14,466 & 14,34 & 0,9913 & 123,2 & 14,48 & 15,06 & 1,0401 \\
\hline-1085 & 123 & 14,466 & 14,92 & 1,0314 & 123,2 & 14,48 & 14,79 & 1,0214 \\
\hline-997 & 123 & 14,466 & 15,16 & 1,0480 & 123,2 & 14,48 & 14,64 & 1,0110 \\
\hline-895 & 123 & 14,466 & 15,21 & 1,0514 & 123,2 & 14,48 & 14,59 & 1,0076 \\
\hline-778 & 123 & 14,466 & 15,18 & 1,0494 & 123,2 & 14,48 & 14,71 & 1,0159 \\
\hline-648 & 123 & 14,466 & 15,2 & 1,0507 & 123,2 & 14,48 & 14,61 & 1,0090 \\
\hline-458 & 123 & 14,466 & 15,22 & 1,0521 & 123,2 & 14,48 & 14,6 & 1,0083 \\
\hline-208 & 123 & 14,466 & 15,19 & 1,0500 & 123,2 & 14,48 & 14,69 & 1,0145 \\
\hline 0 & 123 & 14,466 & 15,11 & 1,0445 & 123,2 & 14,48 & 14,61 & 1,0090 \\
\hline 0 & 123,3 & 14,48 & 14,99 & 1,0352 & 123,3 & 14,49 & 14,73 & 1,0166 \\
\hline 208 & 123,3 & 14,48 & 14,93 & 1,0311 & 123,3 & 14,49 & 14,71 & 1,0152 \\
\hline 458 & 123,3 & 14,48 & 14,97 & 1,0338 & 123,3 & 14,49 & 14,74 & 1,0173 \\
\hline 648 & 123,3 & 14,48 & 15,06 & 1,0401 & 123,3 & 14,49 & 14,98 & 1,0338 \\
\hline 778 & 123,3 & 14,48 & 15,04 & 1,0387 & 123,3 & 14,49 & 15,01 & 1,0359 \\
\hline 895 & 123,3 & 14,48 & 15,05 & 1,0394 & 123,3 & 14,49 & 14,9 & 1,0283 \\
\hline 997 & 123,3 & 14,48 & 14,93 & 1,0311 & 123,3 & 14,49 & 14,89 & 1,0276 \\
\hline 1085 & 123,3 & 14,48 & 14,7 & 1,0152 & 123,3 & 14,49 & 14,95 & 1,0317 \\
\hline 1160 & 123,3 & 14,48 & 14,29 & 0,9869 & 123,3 & 14,49 & 15,11 & 1,0428 \\
\hline 1220 & 123,3 & 14,48 & 13,87 & 0,9579 & 123,3 & 14,49 & 15,18 & 1,0476 \\
\hline 1250 & 123,3 & 14,48 & 13,25 & 0,9151 & 123,3 & 14,49 & 15,06 & 1,0393 \\
\hline
\end{tabular}

\section{The rear operation section}

Test section provides turbulent flow with the height - depending structure of the surface of the atmospheric boundary layer above terrain of specific roughness in the scale 1:300 - 1:400. Model tests in this part enable to detect local pressure, surface and overall wind load under various wind directions using the turn table and to determine mean and fluctuation wind load of structures having atypical special shapes for which the wind effects are not specified in standards. This sector is also proper for assessment of wind effects upon the pedestrians as well as for monitoring of wind comfort in built-up areas.

\section{Simulation of the ABL}

The mean velocity profile above FUR terrain (FUR - Flat Uniformly Rough) up to the geostrophic height can be formed in works by Panofsky and Dutton [7]. The thickness of the ABL is defined like height, where surface shear stresses may be neglected and wind velocity is constant. The vertical line of the mean wind velocity by the neutral air flow should be defined by logarithmic law (1).

$v_{m}(z)=\left(u_{*} / \kappa\right) \cdot \ln \left(z / z_{0}\right)$

where $u_{*}=\sqrt{\tau_{0} / \rho}$ is frictional speed,

$\tau_{0} \quad$ is shear stress at the ground,

$\rho \quad$ is air density,

$\kappa=0,4$ is von Kármán coefficient, 
$z_{0} \quad$ is parameter, which describes logarithmic law profile of the mean wind velocity above different roughness of the terrain (height of extrapolation to the mean wind $=0$ ).

Aerodynamic roughness lengths according Wieringa for different types of terrain can be formed in [6].

The mean wind velocity due to EN 1994-1-4 [1] depends on terrain roughness and is defined up to $200 \mathrm{~m}$ by logarithmic law:

$$
\begin{aligned}
& v_{\mathrm{m}}(z)=c_{\mathrm{r}}(z) \cdot c_{\mathrm{o}}(z) \cdot v_{\mathrm{b}}=k_{\mathrm{r}} \cdot \ln \left(z / z_{0}\right) \cdot 1 \cdot v_{\mathrm{ref}} \\
& \text { where } v_{\text {ref }} \quad \text { is basic wind velocity at the height } 10 \mathrm{~m} \text { above terrain FUR (Flat } \\
& \text { Uniformly Rough - Terrain II). } \\
& c_{\mathrm{r}}(z)=k_{\mathrm{r}} \ln \left(z / z_{0}\right) \quad \text { is the roughness factor for } z_{\text {min }} \leq z \leq z_{\text {max }} \\
& k_{\mathrm{r}}=0,19 \cdot\left(z_{0} / z_{0, \mathrm{II}}\right)^{0,07} \quad \text { is terrain factor, depends on the roughness length } z_{0} \text { : } \\
& z_{0} \quad \text { is roughness length, } \\
& z_{\min } \quad \text { is minimum height, } \\
& z_{\max } \quad \text { is } 200 \mathrm{~m} \text {. } \\
& c_{\mathrm{o}}(z) \quad \text { is orography factor } \\
& z_{0, \mathrm{II}}=0,05 \mathrm{~m} \text { (terrain Cat. II), } z_{0}=0,3 \mathrm{~m} \text { (terrain Cat. III), } z_{0}=1 \mathrm{~m} \text { (terrain Cat. IV) }
\end{aligned}
$$

\section{Preparation of the boundary layer}

Simulated boundary layer requires the similarity criteria in four basic parameters:

$1 /$ profile of mean value of longitudinal component of velocity vector,

$2 /$ profile of turbulence intensity of this component,

$3 /$ integral length scale,

4/ power spectral density of vortexes in the air flow.

Velocity profiles must be investigated for different roughness and we are able to obtain information on type and quality of boundary layer. The special devices like grids or foil and 2D barriers (Fig. 4) or Counihan vortex generators are inserted along wind tunnels (see [3], [4], [5]).

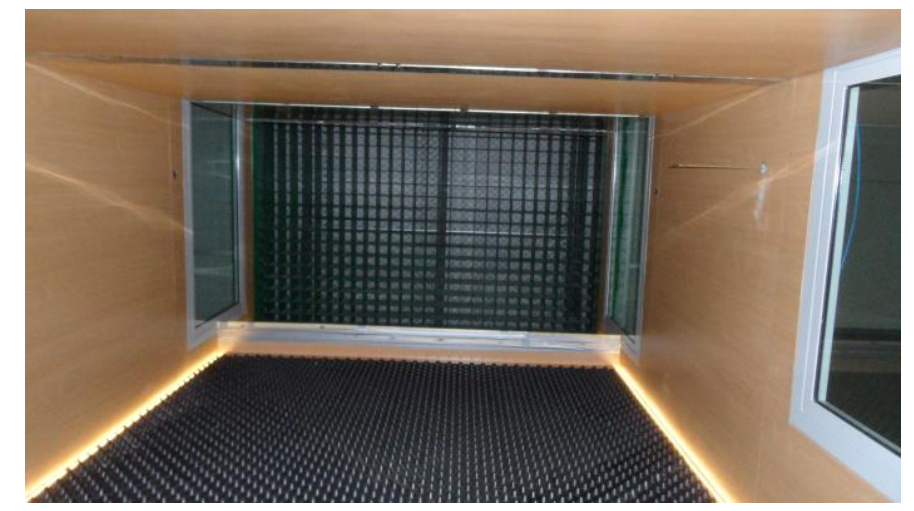

Fig. 4: Arrangement of simulation of boundary layer in BLWT STU (wall $100-250 \mathrm{~mm}$ ).

For this purpose an anemometer with heated wire is a proper device, working on the principle of King's cooling law. CTA (Constant Temperature Anemometry) is used for measuring velocity in a point and continuously provides information on the velocity in time series. Presently the BLWT tunnel is equipped with Mini CTA (Fig. 5, 6), sufficient for simple experiments. 


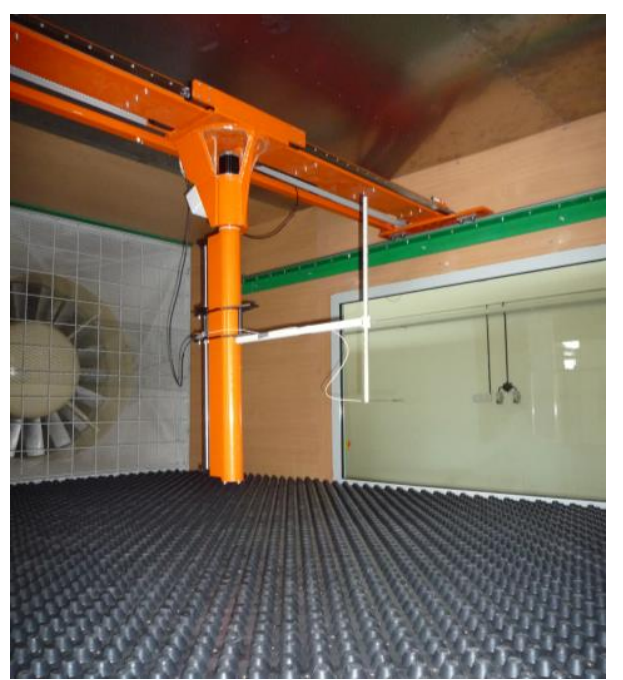

Fig. 5: View on the moveable arm with mini CTA probe.

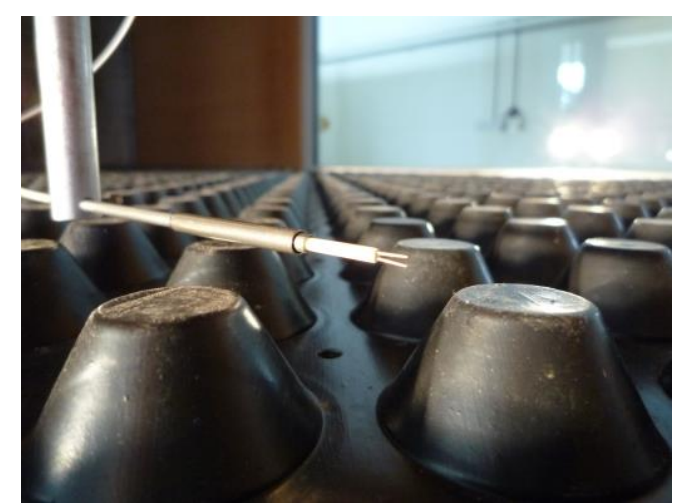

Fig. 6: View of the probe near the rough surface.

The results of the experimental measurements in the preparation of boundary layer and comparison with EN 1991-1-4 are shown in Fig. 7, 8.

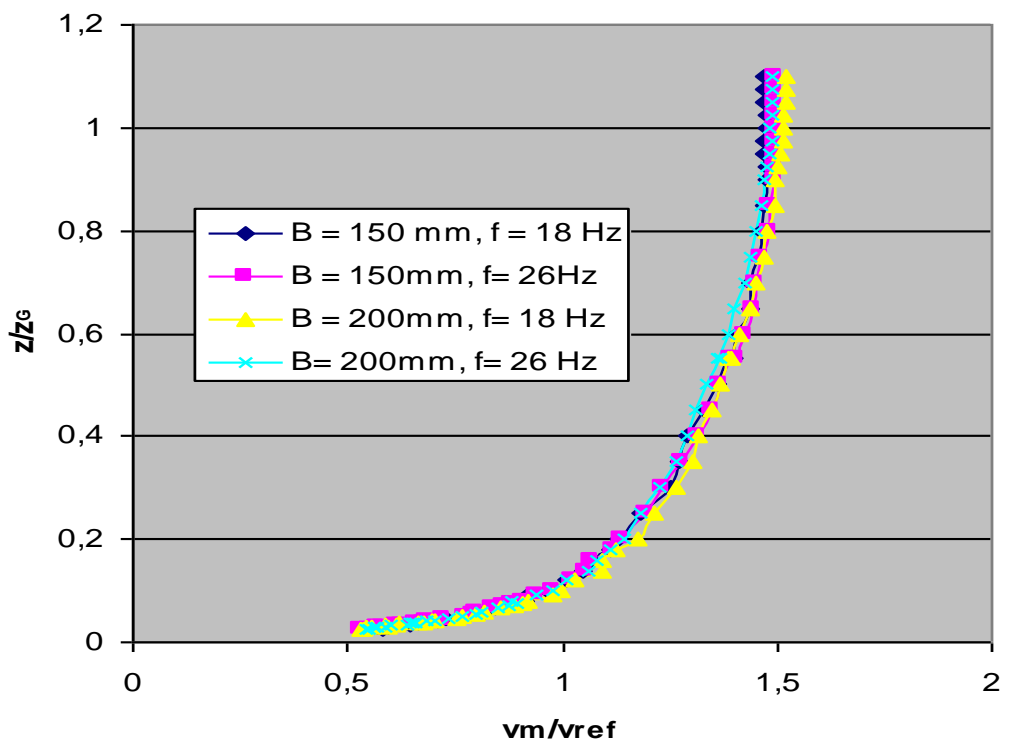

Fig. 7: Experimental measurements of the $v_{\mathrm{m}}(z)$ for different height of barriers $(B)$ and wind velocity. 


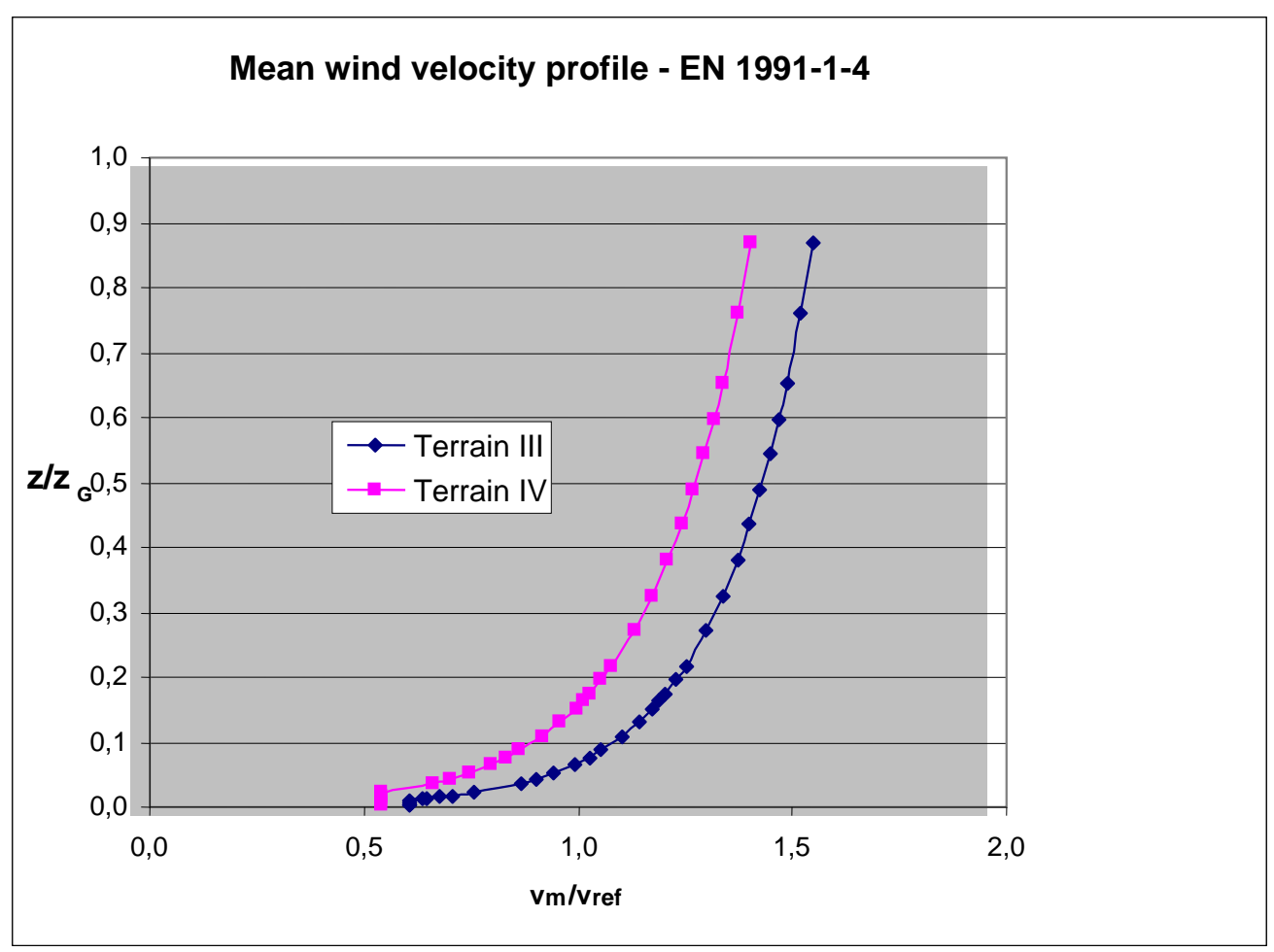

Fig. 8: Mean wind velocity as a function of height and terrain category.

By comparing Fig. 7, 8, we can see, that the prepared boundary layer is between terrain category III and IV.

\section{The turbulence intensity}

The turbulence intensity $I_{\mathrm{v}, \mathrm{i}}(z)$ is defined as the standard deviation of the turbulence divided by mean wind velocity in different directions $(x, y$ and $z$ ). The values of turbulence intensity were developed using micro-meteorological measurement by different researchers (Kaimal, Busch, Panofsky). The rules for determination of $I_{\mathrm{v}, \mathrm{i}}(z)$ without thermal effects are given in expression (4).

$I_{\mathrm{v}, \mathrm{i}}(z)=\frac{\sigma_{\mathrm{i}}(z)}{v_{\mathrm{m}}(z)}=\frac{A_{\mathrm{i}}}{\ln \left(z / z_{0}\right)}=\frac{\kappa \cdot\left(\sigma_{\mathrm{i}} / u^{*}\right)}{\ln \left(z / z_{0}\right)}$

For along wind part $A_{\mathrm{i}}=1$, for crosswind part $A_{i}=0,8$ and for vertical part $A_{i}=0,5$.

In general, the longitudinal turbulent component is the most significant with respect to the response of a structure.

The similar distribution of the turbulence intensity for along wind is given in EN 1994-1-4 (5).

$I_{\mathrm{v}}(z)=\frac{\sigma_{v}(z)}{v_{m}(z)}=\frac{k_{I}}{\mathrm{c}_{\mathrm{o}}(\mathrm{z}) \cdot \ln \left(z / z_{0}\right)}=\frac{1}{\mathrm{c}_{\mathrm{o}}(\mathrm{z}) \cdot \ln \left(z / z_{0}\right)}$

The results of the experimental measurements of boundary layer and comparison with EN 1991-1-4 are shown in Fig. 9, 10. 


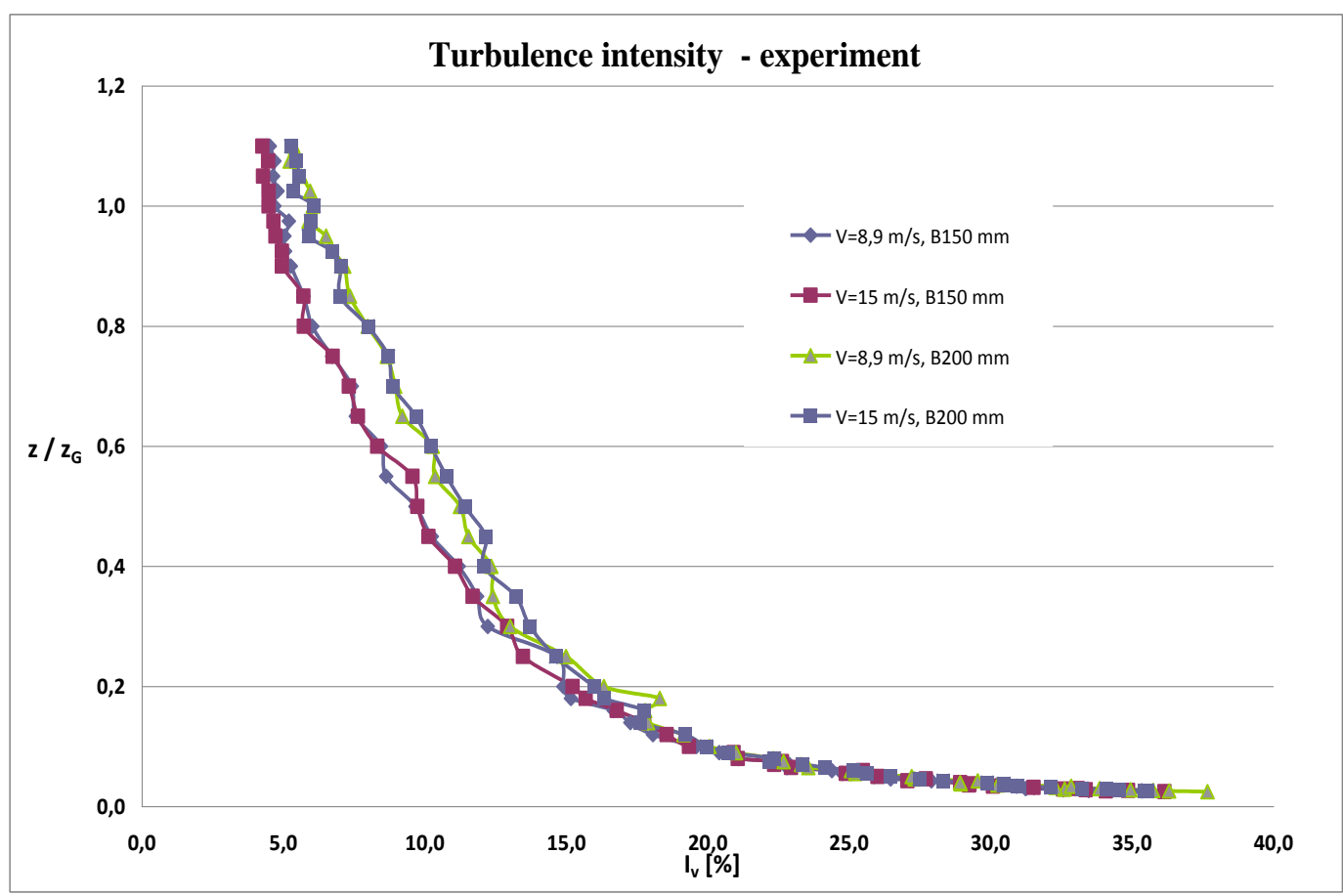

Fig. 9: Experimental measurements of the $I_{\mathrm{v}}(z)$ for different height of barriers $(B)$ and wind velocity.

By comparing Fig. 9, 10, we can see, that the prepared boundary layer with turbulence intensity is between terrain category III and IV.

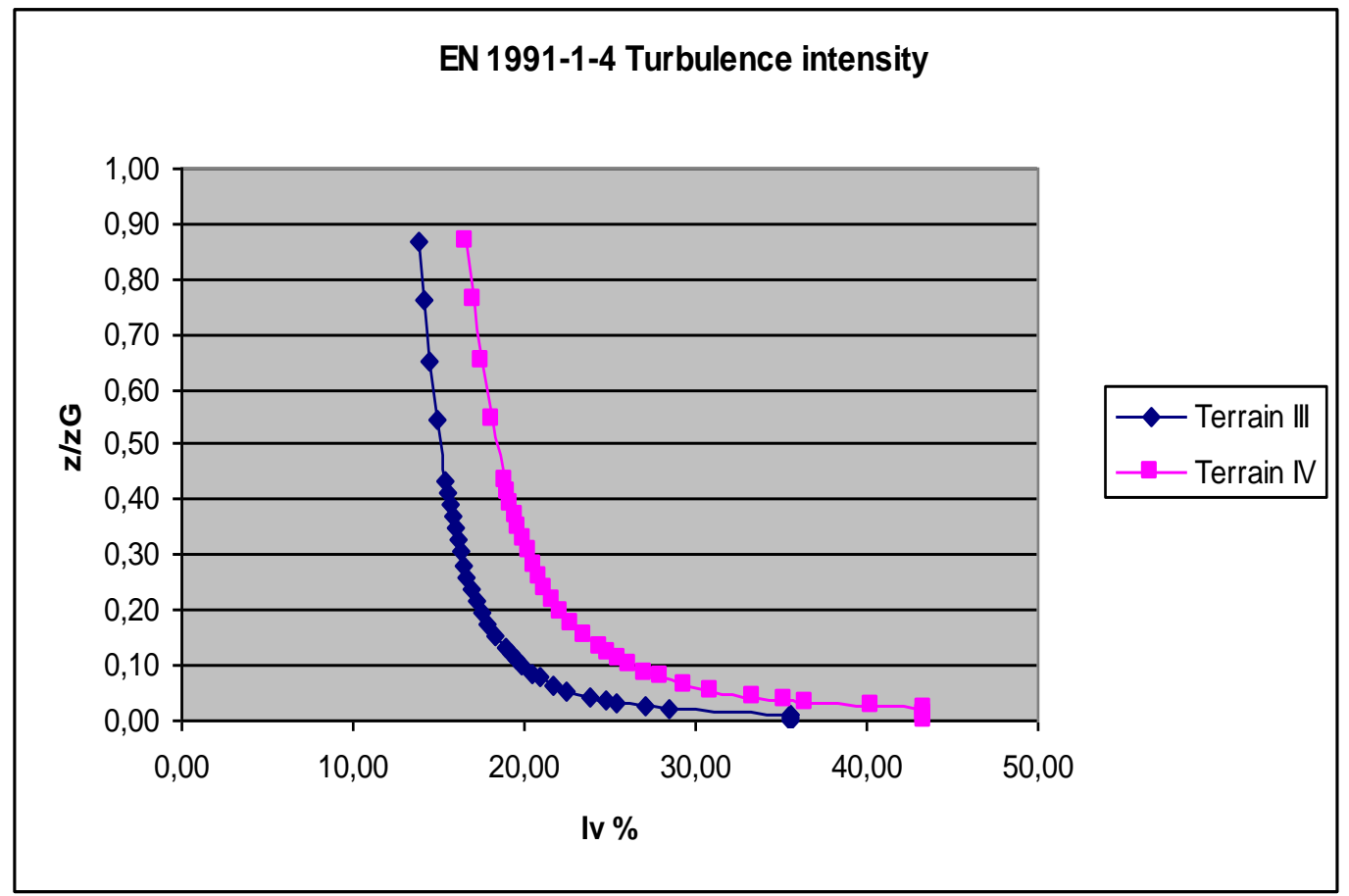

Fig. 10: The turbulence intensity as a function of height and terrain category. 


\section{The integral length scale}

The turbulent length scale represents the average gust size for natural wind. For height $z$ and for along wind part of turbulence should be determined by expression (6):

$L_{\mathrm{u}, \mathrm{x}}(z)=v_{m}(z) \int_{0}^{\infty} \frac{R_{u u}(\tau)}{\sigma_{u}^{2}} d \tau$

where $R_{u u}(\tau)$ is autocorrelation function of fluctuating part in wind direction and $\sigma_{u}^{2}$ is the variance of along wind velocity.

According to Counihan [8] integral length of turbulence can be expressed as follows:

$L_{\mathrm{u}, \mathrm{x}}=300 \cdot(z / 300)^{\varepsilon}$

$\varepsilon=0,46+0,074 \cdot \ln \left(z_{0}\right)$

The modify expression for the turbulent length scale $L(z)$ can be find in Annex B EN 1991-1-4 [1] where length scale depend on roughness length $z_{0}$.

$L(z)=300 \cdot\left(\frac{z}{200}\right)^{0,67+0,05 \ln \left(z_{0}\right)}$

Experimental measurement in BLWT STU and comparison with Counihan [8] and EN code [1] are presented in Fig. 11.

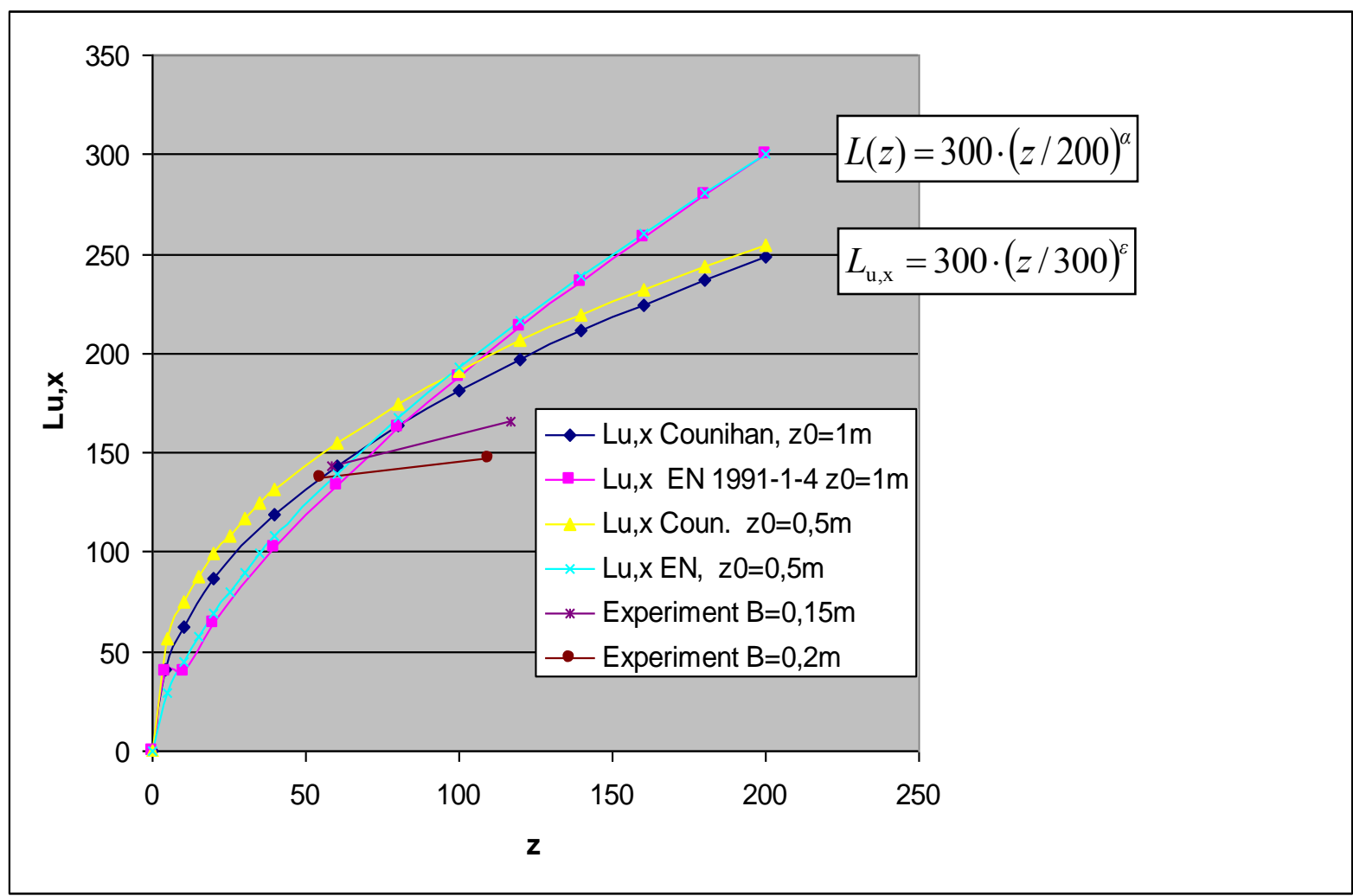

Fig. 11: The integral length scale for terrain category IV - III and experimental results in BLWT STU. 


\section{Conclusions}

The paper shows that detailed measurements of the wind action, especially near the ground, help us to prepare boundary layer in BLWT STU according to EN 1991-1-4. It is necessary to compare various measurements with different barriers (height $B=0,1-0,25 \mathrm{~m}$ ) and choose optimal parameters for roughness in wind tunnel. By comparing the velocity and turbulence of the surface layer we could classify terrain roughness between the III and IV according to EN 1991-1-4 standard, which corresponds to the roughness of terrain in Bratislava. The basic design characteristics of the boundary layer, i.e. components of the time and height dependent wind velocity vector, give us roughness len $z_{0}$, turbulence length scales $L_{v}(z)$ and power spectral density function $S_{v}(n)$. Experimental measurements in BLWT STU so far have ensured height of boundary layer about 1,05 m and SF $366-390$. Due to the fact that the roughness length for area with regular cover of buildings or vegetation - terrain category III $z_{0}=0,3 \mathrm{~m}$, our boundary layer in wind tunnel with value $z_{0}=0,7-0,77 \mathrm{~m}$ is closer to the terrain category IV (area with at least $15 \%$ of the surface covered with buildings while their height exceeds $15 \mathrm{~m}$ ), where $z_{0}=1 \mathrm{~m}$.

\section{Acknowledgement}

The presented results were achieved under sponsorship of the Grand Agency VEGA of the Slovak Republic (grant. reg. No. 1/0480/13).

\section{References}

[1] EN 1991-1-4 Eurocode 1: Actions on structures-Part 1-4: General actions-Wind actions 2005.

[2] PIRNER, M. - FISCHER, O.: Zatížení staveb větrem, vydalo ČKAIT Praha 2003, ISBN 80-8676910-0.

[3] JIRSÁK, M. - HORA, A. - KRÁL, J.: Větrný tunel VZLÚ/KÚ ČVUT pro modelové zkoušky staveb. Letecký zpravodaj č.1, 8-15 VZLÚ 1997.

[4] ACSE Manuals and Reports on Engineering Practice, no.67. Wind Tunnel studies of buildings and structures. Aerospace Division of the American Society of Civil Engineers. Preklad Jirsák, M.: Studie budov a konstrukcí ve vetrných tunelech., ČKAIT Praha, 2009, ISBN 978-80-87093-87-0.

[5] JIRSÁK, M. - KRÁL, J.: A new wind tunnel VZLÚ/KÚ for wind engineering, EECWE' 94 paper, Warszaw 1994.

[6] WIERINGA, J.: Representative Roughness Parameters for Homogeneous Terrain. Boundary Layer Meteorology, 63, p. 323-363, 1993.

[7] PANOFSKY, D. A. - DUTTON, J. A.: Atmospheric turbulence: Models and methods for Engineering Applications, Wiley, New York, 1983.

[8] COUNIHAN, J.: An Improved Method of Simulating an Atmospheric Boundary Layer in a Wind Tunnel, Atmosf. Ennviron., 3, p. 197 - 214, 1969.

[9] HUBOVÁ, O.: The effect of the wind on the structure, Slovak Journal of Civil Engineering 2007/3, Volume XV, pp. ISSN 1210-3896, 2007.

[10]HUBOVÁ, O.: Aeroelasticata, Statické a dynamické účinky vetra na stavebné konštrukcie, vydavatel'stvo STU Bratislava, ISBN 978-80-227-3886-6, 2013. 